\title{
The interrelationships between resource-holding potential, resource-value and reproductive success in territorial males: How much variation can we explain?
}

\author{
Clint D. Kelly
}

Received: 5 July 2007 /Revised: 2 October 2007 / Accepted: 24 October 2007 / Published online: 21 December 2007

(C) Springer-Verlag 2007

\begin{abstract}
A long-standing hypothesis in behavioural ecology posits that males with greater resource-holding potential (RHP) control resource sites deemed more valuable by sexually-receptive females and, thereby, males controlling such sites accrue greater reproductive success (RS). This hypothesis has historically been investigated using three separate but non-mutually exclusive relationships (male RHP vs. resource value, resource value vs. male RS and male RHP vs. RS). The relationships between these three variables are predicted to be strongly positive, however, due to measurement error and biological noise, perfect correlations $(r=1.0)$ are rare in biology even for well-established relationships. Moreover, the inaccurate identification of either the male trait(s) important to RHP or the resource characteristic sought by females will weaken the observed strength of the relationships. Here, I use meta-analysis to quantitatively describe the general pattern of these relationships in animals. I predict that the relationships between male RHP, resource-value and RS
\end{abstract}

Communicated by A. Cockburn

Electronic supplementary material The online version of this article (doi:10.1007/s00265-007-0518-8) contains supplementary material, which is available to authorized users.

\section{D. Kelly}

Department of Biology, University of Toronto at Mississauga,

Mississauga, Ontario, Canada

C. D. Kelly

School of Botany and Zoology, Australian National University, Canberra, ACT, Australia

Present address:

C. D. Kelly $(\triangle)$

Department of Psychology, Dalhousie University,

Halifax, Nova Scotia, Canada

e-mail: clintkelly@dal.ca should be significantly positive (male RHP and resourcevalue should explain a large amount of the variation in male RS). My meta-analysis supports this hypothesis; however, in the best case scenario only ca. $20 \%$ of the variation in the response variable was explained. I conclude by identifying areas in which we need to improve our investigations of resource-defence animals and recommending approaches to meet these needs.

Keywords Resource-defence $\cdot$ Resource-holding potential . Resource value $\cdot$ Mating success $\cdot$ Sexual selection .

Meta-analysis $\cdot$ Publication bias

\section{Introduction}

Breeding female animals require particular materials from the environment, such as oviposition or egg-laying sites, food and refugia from predators (Emlen and Oring 1977; Thornhill and Alcock 1983). If the resources critical to adult females are economically defendable by single adult males, for example by being spatially or temporally clumped, males can increase their fitness by controlling the resources and exchanging access to them for copulations (Emlen and Oring 1977; Brown et al. 1997). The greater the degree to which resources can be monopolized by males, the greater the variance in male reproductive success and the more intense the sexual selection on male traits favouring control of resources (Emlen and Oring 1977; Shuster and Wade 2003).

Sexually-receptive females should seek the best available resources if their fitness is tied to resource quality, as it often is (Møller and Jennions 2001a). There are six hypotheses explaining how females could assess resource value and decide to settle on particular resource sites or 
territories. These hypotheses assume that males always occupy the resources that the females need unlike, for example, in Hemideina tree weta where empty refuges are occasionally available to females (Kelly 2006c). First, females could choose based on resource value alone if resources are more readily assessed than male quality and if there is little possibility for male deceit about resource value (Searcy 1979). Moreover, if male-male competition for resources acts as a filter to male genetic quality then, by default, females should acquire a high-quality male on a high-value resource. Hence, Brown et al. (1997) suggest that females should be selected to assess resource value and if female mate choice exists, it should be exercised either during or after copulation, not before. It should also be noted that although females could accrue direct fitness benefits by choosing males based on phenotype (e.g. decreased risk of acquiring sexually transmitted diseases, Reynolds and Gross 1990; Kirkpatrick and Ryan 1991), these benefits should be small relative to effects of variation in resource value, particularly if the survival and mating success of a female's offspring are dependent upon the larval environment (e.g. Howard 1978b; Reaney and Backwell 2007).

Second, females could base their choice directly upon the male phenotype if the genetic benefits offered by a male are more critical to offspring fitness than resource value (Pomiankowski 1988) or if male characters indicate nonresource-based direct benefits such as the quality of paternal care (e.g. Downhower and Brown 1980).

Third, females could use male phenotype as a cue to resource value if contests over resources produces a positive association between male phenotype and resource quality (Howard 1978a; Gottlander 1987; Hoi-Leitner et al. 1995). Therefore, females could indirectly choose a highvalue resource by mating with males possessing phenotypic indicators of greater resource-holding potential (hereafter RHP, Parker 1974). For example, controlled field experiments showed that female C. s. xanthostoma damselflies choose to mate and oviposit at particular locations based on the phenotype (degree of wing pigment heterogeneity) of the resident male (Siva-Jothy 1999). Given that resident males tend to also control better oviposition sites, females possibly gain the direct benefits of ovipositing on a higherquality territory in addition to being guarded by a male that is better able to repel harassing conspecific males (SivaJothy 1999). Alternatively, if male genetic quality and resource value are not correlated, females would have the opportunity to choose sires independent of resources (Conrad and Pritchard 1992). For example, female Calopteryx dimidiata damselflies are able to separate mate choice and resource choice because females can mate with a high-quality male and then seek a superior oviposition site elsewhere; given that they oviposit underwater and therefore can submerge and lay eggs free from harassment by the resident male (Waage 1984; see also Forsyth and Montgomerie 1987; Tsubaki and Ono 1987).

Fourth, females may use resource characteristics as a cue to male quality. Again, if the quality of the resource-holding male is positively correlated with resource value, and judging resource value is more difficult than assessing male quality (Waage 1984), females could indirectly acquire high-quality mates by examining resources (e.g. Fincke 1992). Passive female mate choice (Thornhill and Alcock 1983) should provide numerous advantages to females (e.g. avoid the costs of inter-sexual contact such as energy expenditure, physical injury and parasite and disease transmission) if resource value is a reliable predictor of male genetic quality.

Fifth, females could choose a breeding situation based on some combination of male phenotype and resource value (e.g. birds, Yasukawa 1981; fish, Thompson 1986; mammals, Balmford et al. 1992; crustaceans, Backwell and Passmore 1996; insects, Jennions 1998), perhaps by using a threshold-criterion tactic of choice (Wittenberger 1983). This would involve selectively weighting the quality of both the male and the resource and then combining them into a single index of suitability. Alternatively, females could use a two-step process whereby all males are assessed based on one component and then a subset of those are judged on the second component (Thornhill 1983; Backwell and Passmore 1996). In either case, females should give priority to resource quality because of their immediate benefits (Møller and Jennions 2001a); hence, females should mate with the first male encountered who meets her minimum criteria (Wittenberger 1983).

The final hypothesis is the null model of random female settlement (Wootton et al. 1986) or neutral-mate-choice (Lightbody and Weatherhead 1988). Although the neutralmate-choice hypothesis is a null model and female choice is random, it is not a 'truly' null model because neutral choice predicts female behaviour to be optimal with respect to maximizing fitness whereas a true null model of random choice predicts that female settlement is not optimal (Lightbody and Weatherhead 1988). Both models predict that males with larger territories acquire more female mates (i.e. harem size correlates positively with territory/resource area) (Lightbody and Weatherhead 1988).

If females preferentially settle on the best available resources and males with greater RHP control these resources, then a strong positive relationship between male RHP, resource quality and male mating success is predicted, perhaps even reaching $r=1.0$ if rank-based methods are used (e.g. Spearman rank or Kendall tau correlation). Due to measurement error and biological noise, perfect correlations $(r=1.0)$ are, however, rare in biology even for wellestablished relationships (Jennions et al. 2001; Møller and Jennions 2002). Moreover, the inaccurate identification of either the male trait(s) important to RHP or the resource 
characteristic sought by females will weaken the observed strength of the relationships.

If sexually receptive females are more strongly attracted to higher-quality resources and males with greater RHP monopolize these resources (Fig. 1 Scenario 1a and b), then males with larger RHP should have greater reproductive success (Fig. 1 Scenario 1c). Many studies have investigated this hypothesis by determining whether dominant males
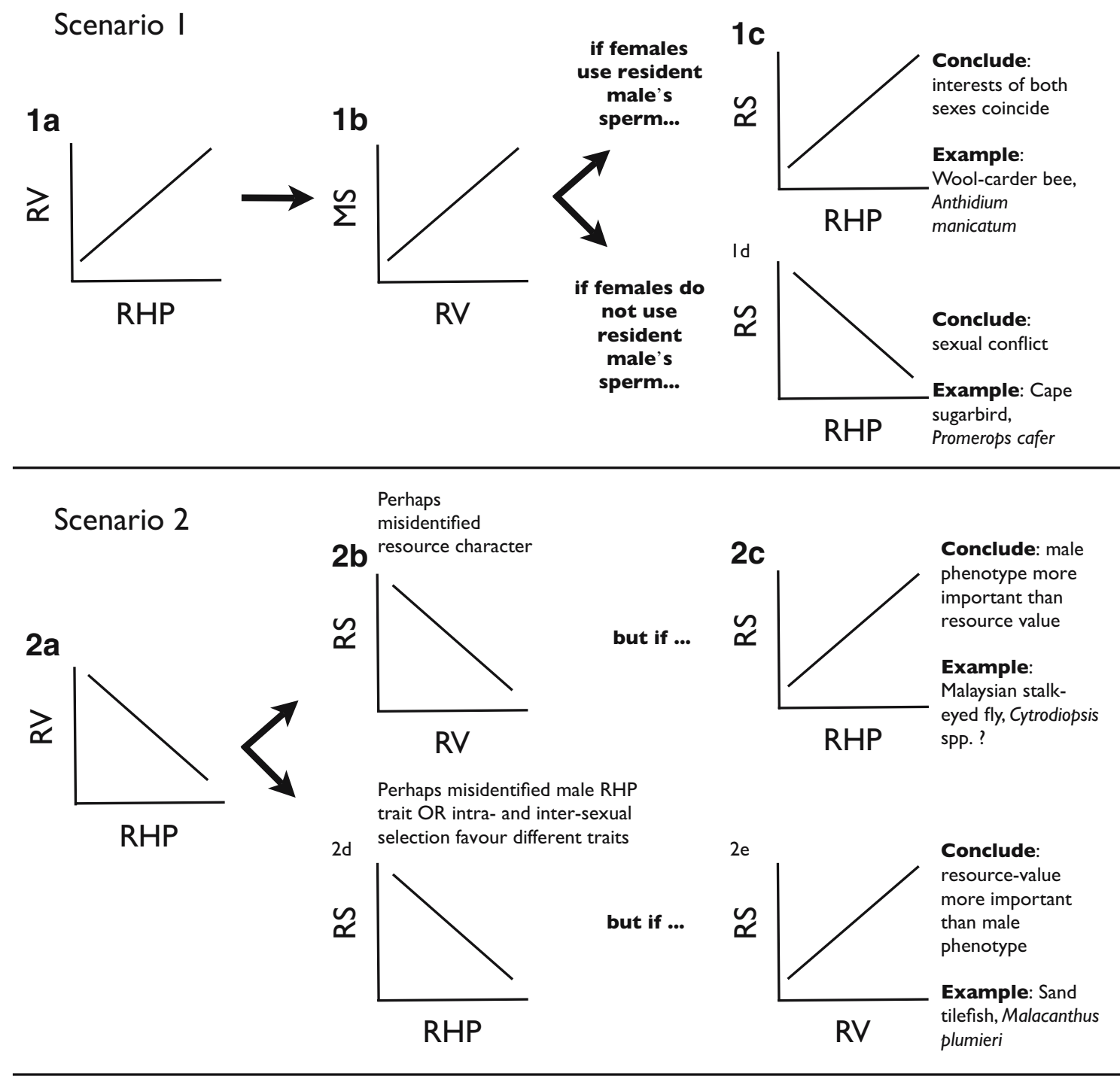

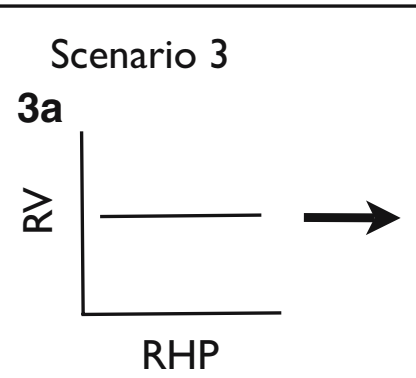

Perhaps misidentified male RHP trait AND

3b resource character

Fig. 1 The importance of testing each relationship among resourcevalue (RV), male resource-holding potential (RHP) as well as male reproductive (RS) and reproductive (RS) success within a species. Each scenario presents the possible mechanisms driving either a positive (Scenario 1), negative (Scenario 2) or no (Scenario 3) correlation between RV vs. RHP. Alternative hypotheses for a given relationship are presented above figures. For example, if a positive correlation is found between RV

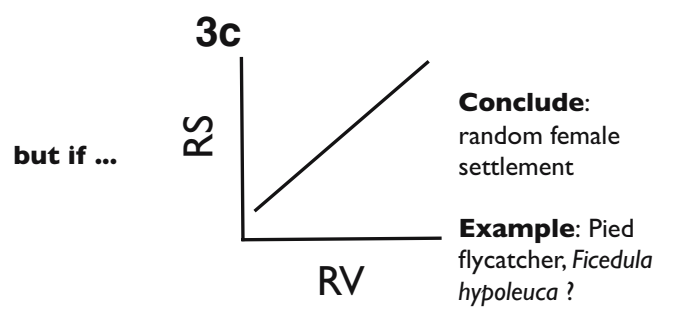

vs. RHP (Scenario 1a), does this mean that males with greater RHP have greater RS because they own sites having greater RV (Scenario 1c)? No, because although more females may visit (and potentially mate) at sites having greater RV (Scenario $1 b$ ), females may prefer to use the sperm of males with lower RHP (Scenario 1d). This would arise if, perhaps, there were a trade-off among male traits selected by malemale competition versus female mate choice 
(i.e. those whose RHP is inferred to be greater) have increased reproductive success (e.g. Gwynne and Jamieson 1998; Kelly 2005). This is problematic because a correlative estimate of a single relationship cannot reveal the underlying mechanisms driving male reproductive success (Fiske et al. 1998). In many cases (e.g. Kelly 2005), concluding that males with large RHP also have higher reproductive success implicitly assumes that the first two statements are correct (i.e. RHP vs. RV and RV vs. MS) (Fig. 1 Scenario $1 \mathrm{a}-\mathrm{b}$ ) and also assumes that mating success equals reproductive success (Brown et al. 1997). That mating success equals reproductive success is a safe assumption (e.g. Côte and Hunte 1989); however, if intense sexual conflict arises and females prefer to use the sperm of males with traits unrelated to RHP then resource-defence should breakdown (Fig. 1 Scenario 1d) (Brown et al. 1997; Arnqvist and Rowe 2005).

Quantifying the strength of one relationship and assuming the other two to be correct does not test all relationships directly and therefore cannot be used to infer that males with greater RHP hold better resources or that better resources attract more females. In other words, correlating a single factor (e.g. male RHP) with mating or reproductive success only explains part of the puzzle of what attracts females to certain locations and why particular males reside at those locations. For example, a negative relationship between RV and male RHP from an observational field study (e.g. Baird 1988), can be caused by a number of factors (Fig. 1 Scenario 2): perhaps there is a stronger female preference for either the resource or male phenotype, trade-offs might exist because male traits that increase success during male combat decrease male attractiveness to mate choosing females, or perhaps the relationship is a product of either a misidentified resource-character or male RHP trait. By further investigating each of the other two relationships (RS vs. RV and RS vs. RHP; Fig. 1 Scenario $2 \mathrm{~b}-\mathrm{e}$ ) investigators can gain a better understanding of why males with larger RHP apparently hold poorer resources. For example, if resource-value is negatively correlated with reproductive success (Fig. 1 Scenario $2 b$ ) but male RHP is positively correlated with reproductive success (Fig. 1 Scenario 2c), then female mate choice is likely based more on male phenotype than resource value.

Random female settlement would be indicated by a positive relationship between RV (i.e. territory area) vs. RS (Fig. 1 Scenario 3c) and no relationship between RV vs. male RHP (Fig. 1 Scenario 3a) and between RS vs. male RHP (Fig. 1 Scenario 3b). Alternatively, the lack of relationship in Scenarios $3 \mathrm{a}$ and $\mathrm{b}$ could be due to misidentified traits or resource characters.

A central prediction of behavioural ecology is that male RHP, resource quality and male reproductive success are all positively correlated (Emlen and Oring 1977; Andersson
1994; Brown et al. 1997; Shuster and Wade 2003). Although many studies have supported this prediction, other studies suggest that mating with a more dominant male may be costly to females. For example, strong negative relationships have been reported between male RHP and resource-value (e.g. Baird 1988), reproductive success and resource-value (e.g. Villalobos and Shelly 1991; Oliveira et al. 2000) and reproductive success and male RHP (e.g. Savalli 1994a). It is clear that individual studies inadequately describe general patterns in nature. Here, I use meta-analysis to quantitatively describe the general pattern of these relationships in animals. Although others have qualitatively assessed the relationships between male RHP, resource value and male reproductive success in resource-defence animals (e.g. Baker 1983; Fitzpatrick and Wellington 1983; Thornhill and Alcock 1983; Maher and Lott 2000), that approach does not measure the magnitude of the effect size nor does it give any indication as to the sources of variation in effect sizes. I predict that the relationships between male RHP, resource-value and reproductive success should be significantly positive. In other words, I expect that male RHP and resource-value should explain a large amount of the variation in male reproductive success. Additionally, I predict that male RHP and resource value will explain more of the variation in male reproductive success when examined experimentally, rather than by observational studies, because variation due to confounding variables will be eliminated in this type of study. Finally, I also investigated whether effect sizes for the different relationships vary among taxa and whether certain male traits representing RHP have a stronger effect on resourcevalue and reproductive success than other traits.

\section{Materials and methods}

\section{Data sets}

I searched the literature by entering the terms 'resource defence', 'resource defense', 'territoriality', 'territory' and 'territorial' into Web of Science (ISI). I looked for studies reporting information on the relationship between (1) male reproductive success and defended resource-value, (2) male reproductive success and male resource-holding potential and/or (3) resource-value and male resource-holding potential. I make no claim to have included all relevant studies but there is no immediately obvious reason why this search strategy would not yield a representative sample of published studies.

The original authors reported a large number of metrics for male reproductive success and included: the number of females that either copulated, laid eggs, visited a resource patch or associated with a male for a period of time (i.e. harem size); number of offspring hatched, fledged or reared 
to maturity; and pair-bond duration. Resource-value was typically measured as the quantity of some material required by females (e.g. number of flowers, biomass of edible vegetation, proximity to water, degree of predation risk, nest size). In some cases, investigators used male 'ownership' of a resource patch or territory as a metric of resource-value - patches controlled by males were considered to be high-value sites. Male resource-holding potential was defined based on weapon size (e.g. mandible, horn or antler length), body size (e.g. weight, wing, tarsus, pronotum or elytra length), body condition, age, traits that signal fighting ability (e.g. colour patches or song characteristics) and 'other' traits (e.g. experience, residency, date of arrival on a territory). All definitions are those of the original authors: whether the definitions of the original authors are appropriate is not the focus of this paper. The important point to note is that these are how the terms have been defined and used in the literature.

Each study was classified as to whether its methodological approach was experimental or observational. Experimental studies involved manipulating either the trait putatively responsible for defining male RHP and/or the resource character sought by females as well as controlling possible confounding variables (e.g. temperature, light cycle, mating history etc). Most studies were unambiguously classified; however, some studies did not fit the experimental definition. These studies were classified as experimental on the grounds that the investigator manipulated some aspect of the study and so the study was not based on a random set of observations. For example, Wells (1977) observed a sample of frogs that he collected and introduced into an enclosed pond; I classified this as 'experimental'.

\section{Meta-analysis}

I retrieved data from the text or tables or indirectly by measuring figures for each study. I calculated effect sizes as Pearson product-moment correlation coefficients (Hedges and Olkin 1985; Rosenthal 1991; Cooper and Hedges 1994) and transformed data to $r$ using the MetaWin software package (Rosenberg et al. 2000) if presented in another form (e.g. $t, \mathrm{~F}, \chi^{2}$, Mann-Whitney $U$ ). When the means and standard deviations were available I calculated the effect size estimate Hedge's $g$, which was then transformed to $r$.

I followed the protocol used by others (e.g. Jennions et al. 2001; Møller and Jennions 2001a; Torres-Vila and Jennions 2005) and only briefly describe the methodology here. First, correlation coefficients were $z$-transformed and weighted by their sample size. A sample was defined as a single test for an effect.

Samples within studies and multiple studies of a single species lack statistical independence (Thornhill and Møller
1998); therefore, I examined results at the level of samples, studies and species. If qualitatively similar conclusions are reached at all three levels of analysis it is reasonable to assume that the level of analysis is relatively unimportant. The transformed coefficients were combined for each level of analysis and weighted by average sample size per sample within studies or studies within species.

When examining the effect of moderator variables (e.g. male RHP trait-type, resource character, taxon or methodology), I used a single effect for each species for each moderator variable of interest in order to maintain statistical independence. For example, the resource-holding potential of male pheasants, Phasianus colchicus, is influenced by weapons (spurs), body size, signals and age and multiple effect sizes have been calculated for some of these traits. Consequently, a single mean effect size was calculated for each trait for this species and these values were then used in the meta-analysis. There were too few species having both experimental and observational effect sizes available and so could not make paired comparisons (cf. Torres-Vila and Jennions 2005).

Effect sizes were calculated using the mixed-effects model which allows a true random component, in addition to sampling error, as a source of variation in effect size among studies (Hedges and Olkin 1985). The null hypothesis for each analysis was that effect size equalled zero. I tested this hypothesis by examining the 95\% confidence intervals for the mean weighted effect size; overlap with zero would support the null hypothesis at the $0.05 \alpha$-level. MetaWin provides mean effect size and $95 \%$ confidence intervals calculated using a bias-corrected bootstrap approach (999 replicates). Similarly, I examined confidence intervals to see if the mean effect size differed significantly from 1.0. I also report the within-group heterogeneity $\left(Q_{\mathrm{w}}\right)$ for each group of studies, assuming $Q$ follows a $\chi^{2}$ distribution with $d f=$ number of studies -1 . Mean weighted effect sizes $\left(Z_{r}\right)$ were back-converted and are expressed in terms of $r$.

I tested whether the mean effect size differed between groups (e.g. among taxa) by testing for significant betweengroup heterogeneity $\left(Q_{\mathrm{b}}\right)$ using randomisation tests based on 1,000 replicates. Within-group heterogeneity $\left(Q_{\mathrm{w}}\right)$ was calculated for groups with $n_{\mathrm{e}}>5$. If there is no data structure incorporated into the summary analysis (i.e. no moderator variables) then total heterogeneity is calculated $\left(Q_{\mathrm{T}}\right)$ (Rosenberg et al. 2000). I tested whether the magnitude and direction of mean effect sizes are consistent among the three relationships (RHP vs. RV, RHP vs. RS and RV vs. RS) using a subset of species $(n=22)$ in which all three relationships of interest have been reported in the literature. By focusing on this subset of data I control for the effect of species because in the original analysis different species contribute to each of the three relationships and this could, therefore, bias the overall analysis and 
subsequent interpretation. For each species there was a single effect for each relationship. Consequently, I analyzed these data using Cohen's $q$ by calculating the difference in mean effect size per relationship and then testing whether it differs significantly from zero (Rosenthal 1994).

I calculated Rosenthal's fail-safe number for groups with $n_{\mathrm{e}}>5$ to assess the robustness of my results. This estimates the number of studies with no effect that are required to nullify an observed statistically significant effect size at $\alpha=$ 0.05 (Rosenthal 1991). By convention, a conclusion is generally considered robust if the fail-safe number exceeds $5 n_{\mathrm{e}}+10$, where $n_{\mathrm{e}}$ is the reported number of analysis units (i.e. samples, studies or species).

The estimate of a mean weighted effect size could be inaccurate if a publication bias exists (Rosenthal 1991; Begg 1994). This phenomenon has been much debated among meta-analysts (e.g. Rosenthal 1991; Begg 1994; Duval and Tweedie 2000a; Duval and Tweedie 2000b), including evolutionary ecologists (e.g. Arnqvist and Wooster 1995; Palmer 1999; Jennions and Møller 2002; Kotiaho and Tomkins 2002; Koricheva 2003; Jennions et al. 2004; Tomkins and Kotiaho 2004; Møller et al. 2005). The only direct method to address this problem is to compare published and unpublished studies. Several recent studies (Møller and Thornhill 1998; Jennions et al. 2001; Møller and Jennions 2001a; Koricheva 2003; Møller et al. 2005) have done this and, in each case, the effect sizes of the two categories of studies did not differ. I did not have access to unpublished data so I used two indirect methods to address this issue.

First, I calculated the Begg-Mazumdar correlation between standardized effect size and study sample size ( $r$-bias). This statistic should be interpreted with caution, however, because it has low statistical power with sample sizes $\left(n_{\mathrm{e}}\right)$ fewer than 25 (Møller and Jennions 2001b).

Second, I used the iterative 'trim and fill' method of Duval and Tweedie (2000a, b) to estimate the number of 'missing' studies based on a funnel plot of the data (i.e. effect size vs. sample size) and then calculated the mean effect if these hypothetical 'missing' studies are included. This procedure is based on two assumptions: there should be a symmetric distribution of observed effect sizes around the 'true' effect size if publication bias is absent and the most extreme results, typically those with low sample size and high variance, have not been published.

Third, I tested whether there was a correlation between date of publication and effect size.

\section{Results}

As species are the focus of this review and all three levels of analysis (i.e. samples, studies and species) gave similar results, I present and discuss only those findings from the species-level of analysis. The results from the sample- and study-levels of analysis, as well as raw data, are provided as Electronic Supplemental Material (S1 to S4).

Male resource-holding potential vs. resource-value

For the 53 species (from $n=63$ studies), the weighted average effect size of $r=0.37$ was significantly greater than zero and the variation in effect size was no more than expected due to sampling error (Table 1). There was no evidence of publication bias (Table 1; Fig. 2a) and the addition of one putative missing study resulted in a slightly reduced corrected mean effect size of $r=0.35$ (95\% C.I.: $0.27-0.43)$. The mean effect size for experimental studies $(r=0.51,95 \% \mathrm{CI}: 0.35-0.68)$ was larger than for observational studies ( $r=0.35,95 \%$ CI: $0.24-0.44)$ but the difference was not significant $\left(Q_{\mathrm{b}}=2.44, d f=1, P=\right.$ $0.14)$. For each of the six types of male traits used as indices of RHP, individuals with larger values controlled resources of greater value (Table 1). The strength of these relationships was remarkably consistent for the different types of traits $\left(Q_{\mathrm{b}}=0.58, d f=5, P=0.99\right)$. An analysis by taxon (each species contributing one effect size) showed that mean weighted effect size was significantly greater than zero for all taxa but fish (Table 1). There was also no difference in effect sizes among taxa $\left(Q_{\mathrm{b}}=0.96, d f=2\right.$, $P=0.59$; only tested using taxa with $n_{\mathrm{e}}>5$ species).

\section{Resource-value vs. male reproductive success}

The weighted average effect size for the 40 species of $r=$ 45 (from $n=45$ studies) was significantly greater than zero but the among-effect size variation was statistically significant (Table 2). This significant heterogeneity was caused by a single large effect size for the walnut fly Rhagoletis boycei $(r=0.99$; Papaj 1994). Its removal considerably lowered the observed heterogeneity $\left(Q_{\mathrm{w}}=51.2, d f=38\right.$, $P=0.05)$ but did not change the original conclusion (recalculated $r=0.41,95 \%$ CI: $0.32-0.51, \mathrm{n}=39$ ). Partial correlations were performed for three species with a mean effect size of $r=0.17$ ( $95 \%$ CI: $0.05-0.30)$. A trim and fill analysis suggested that six studies were missing (see also Fig. 2b) and the corrected mean effect size of $r=0.34(95 \%$ CI: $0.27-0.41)$ was smaller but still significantly greater than zero. The mean effect sizes for observational $(r=0.45$, 95\% CI: $0.31-0.59)$ and experimental studies $(r=0.44$, $95 \%$ CI: $0.25-0.61)$ did not differ significantly $\left(Q_{\mathrm{b}}=\right.$ $0.004, d f=1, P=0.95)$. The significant variation in effect size was not explained by differences between estimates based on the two main categories of resource value (quality or size) $\left(Q_{\mathrm{b}}=0.10, d f=1, P=0.81\right)$. Mean effect sizes for estimates based on territory quality, size and ownership 
Table 1 Summary of mean effect sizes (Pearson's $r$ with 95\% bias-corrected bootstrapped confidence intervals) for the relationship between resource-holding potential (RHP) and resource-value (RV) at the species level of analysis

\begin{tabular}{|c|c|c|c|c|c|c|c|c|}
\hline & \multicolumn{3}{|c|}{ Effect size } & \multicolumn{3}{|c|}{ Effect size heterogeneity ${ }^{a}$} & \multirow[b]{2}{*}{ Fail-safe no. } & \multirow[b]{2}{*}{$r$-bias } \\
\hline & $n_{\mathrm{e}}$ & $r$ & $95 \% \mathrm{CI}$ & $Q_{\mathrm{w}}$ & $d f$ & $P$ & & \\
\hline All species & 53 & 0.37 & $0.28-0.46$ & $49.2^{\mathrm{b}}$ & 52 & 0.58 & $933^{\mathrm{c}}$ & -0.20 \\
\hline Weapon & 7 & 0.29 & $0.17-0.40$ & 5.2 & 6 & 0.51 & 39 & 0.0 \\
\hline Signal & 13 & 0.31 & $0.22-0.43$ & 11.8 & 12 & 0.46 & $126^{\mathrm{c}}$ & 0.0 \\
\hline Age & 5 & 0.38 & $0.03-0.70$ & 2.7 & 4 & 0.61 & 0 & -0.1 \\
\hline Body size & 38 & 0.37 & $0.25-0.47$ & 35.2 & 37 & 0.55 & $423^{c}$ & -0.25 \\
\hline Body condition & 8 & 0.39 & $0.26-0.55$ & 6.4 & 7 & 0.49 & 45 & -0.36 \\
\hline Other & 5 & 0.33 & $0.08-0.57$ & 4.5 & 4 & 0.35 & 3 & -0.21 \\
\hline Insect & 25 & 0.36 & $0.24-0.47$ & 19.1 & 24 & 0.75 & $191^{\mathrm{c}}$ & -0.27 \\
\hline Bird & 10 & 0.41 & $0.22-0.58$ & 9.5 & 9 & 0.39 & 36 & -0.07 \\
\hline Fish & 8 & 0.23 & $-0.12-0.47$ & 5.5 & 7 & 0.59 & 0 & -0.48 \\
\hline Mammal & 3 & 0.22 & $0.19-0.24$ & - & - & - & - & - \\
\hline Crustacean & 2 & 0.14 & $0.04-0.24$ & - & - & - & - & - \\
\hline Amphibian & 4 & 0.68 & $0.50-0.86$ & - & - & - & - & - \\
\hline Reptile & 1 & 0.80 & - & - & - & - & - & - \\
\hline
\end{tabular}

Data were grouped on the basis of RHP trait (e.g. weapon, signal etc.) and higher taxa (e.g. insect, bird etc). Within-group heterogeneity in effect sizes $\left(Q_{\mathrm{w}}\right)$, Rosenthal's fail-safe number, the Begg-Mazumdar correlation between standardized effect size and sample size $(r$-bias) and the number of effect sizes $\left(n_{\mathrm{e}}\right)$ are provided

${ }^{\text {a }}$ Does not include taxa with $n_{\mathrm{e}}<5$

${ }^{\mathrm{b}} Q_{\mathrm{T}}$ because no data structure

${ }^{c}$ Rosenthal's fail-safe number greater than $5 n_{\mathrm{e}}+10$

were all significantly greater than zero, but only those for resource quality exhibited significantly greater variation than expected due to sampling error (Table 2).

Males holding higher quality resources had significantly greater reproductive success in all major taxa except Crustacea (Table 2). There was no significant difference in the mean effect size among taxa with $n_{\mathrm{e}}>5\left(Q_{\mathrm{b}}=0.66\right.$, $d f=2, P=0.85)$. There was high heterogeneity within each taxa (Table 2) but this was due to a single outlier in each taxa. Removal of these outliers removed the observed heterogeneity within each taxon (Table 2).

Male resource-holding potential vs. male reproductive success

The weighted average effect size of $r=0.37$ (from $n=69$ studies) was significantly greater than zero and the variation among effect sizes was not statistically significant (Table 3). Partial correlations were performed for four species and the mean effect size was not significantly different from zero $(r=0.31,95 \%$ CI: $-0.14-63)$. There was no publication bias (Table 3; Fig. 2c). A "Trim and Fill" analysis suggested that there were 10 "missing" studies and their addition actually resulted in a larger corrected mean effect size of $r=0.47$ ( $95 \%$ CI: $0.37-0.55$ ). The mean effect size for experimental studies $(r=0.63,95 \% \mathrm{CI}$ : $0.30-0.88)$ was significantly greater than that for observational studies $\left(r=0.34,95 \%\right.$ CI: $0.24-0.43 ; Q_{\mathrm{b}}=6.83, d f=1, P=$ 0.009). The type of male trait used to estimate RHP did not explain a significant amount of variation in effect sizes $\left(Q_{\mathrm{b}}=2.4, d f=4, P=0.66\right.$; only traits with $\left.n_{\mathrm{e}}>5\right)$. When analysed by trait type, only those categorized as 'other' has a statistically non-significant mean effect size (Table 3). Similarly, taxon did not explain a significant amount of variation in effect sizes $\left(Q_{\mathrm{b}}=1.03, d f=2, P=0.60\right.$; only taxa with $n_{\mathrm{e}}>5$ ).

\section{Comparison of species-level effect sizes}

In line with the predictions of Scenario 1 (Fig. 1) there was no difference among mean global effect sizes calculated for each of the three relationships (RHP vs. RV: $r=0.37$, RV vs. RS: $r=0.45$ and RHP vs. RS: $r=0.37 ; Q_{\mathrm{b}}=1.8$, $d f=2, P=0.47)$.

Effect sizes for all three relationships were available for 22 species (Table 4: Fig. 3). An analysis of this subset again supports the predictions of Scenario 1 (Fig. 1) because the mean effect size did not differ among the three relationships (RHP vs. RS - RV vs. RS, Cohen's $q=0.012,95 \%$ CI: $0.13-0.15$; RHP vs. RS - RHP vs. RV, $q=0.11,-0.04-$ 0.25 ; RV vs. RS - RHP vs. RV, $q=0.11,-0.03-0.26$ ). However, inspection of an interaction plot (Fig. 3) suggests an interaction between species and relationship-type; suggesting that Scenarios 2 and 3 (Fig. 1) can better explain the interrelationships within some species than Scenario 1.

The three relationships also did not differ when considering only effect sizes from experimental studies (RHP vs. RS - RV vs. RS, Cohen's $q=0.28,95 \%$ CI: $-0.58-$ 

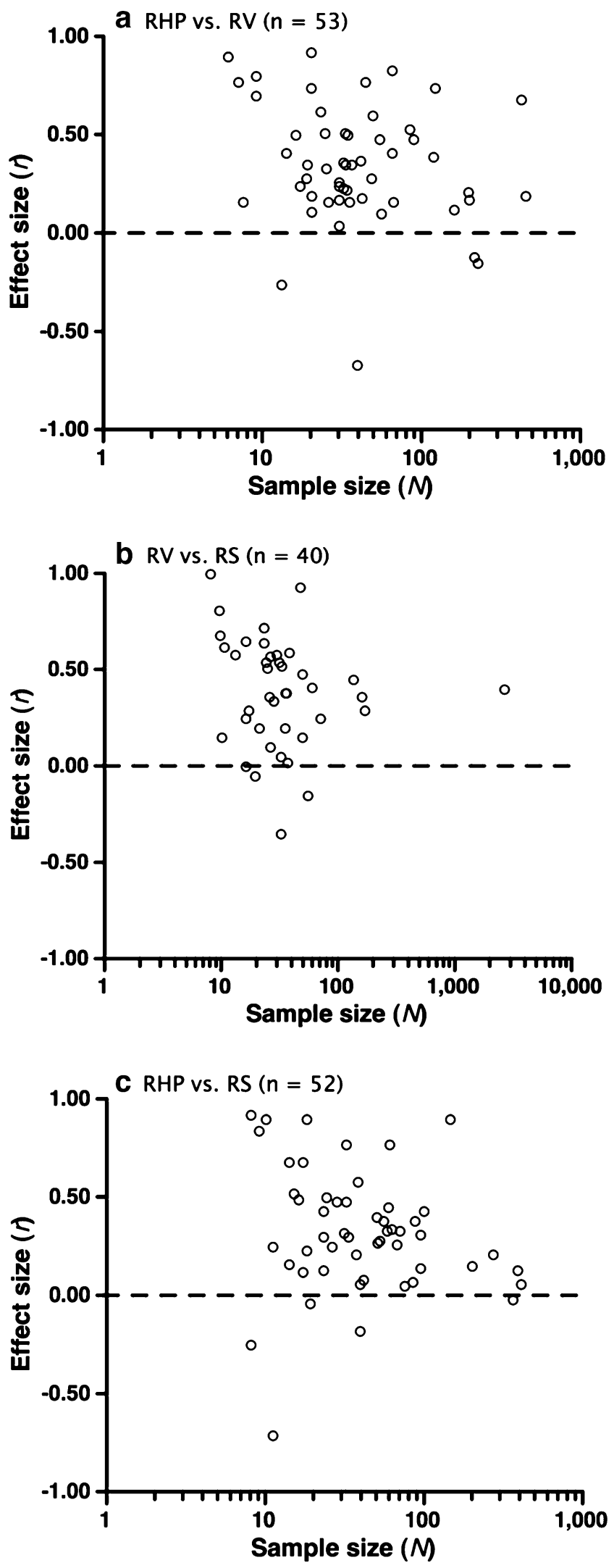

Fig. 2 The relationship between study sample size $(N)$ and effect size $(r)$ at the species-level of analysis for the relationship between a resourceholding potential (RHP) and resource-value (RV), b resource-value (RV) and male reproductive success (RS) and c resource-holding potential (RHP) and male reproductive success (RS). The dashed line represents an effect size of zero and the solid line is for the observed weighted mean effect size

0.96 ; RHP vs. RS - RHP vs. RV, $q=0.18,-0.54-0.77$; RV vs. RS - RHP vs. RV, $q=0.10,-0.58-0.29)$.

\section{Discussion}

A long-standing hypothesis in behavioural ecology posits that males with greater resource-holding potential control resource sites or territories deemed more valuable by sexually-receptive females and, thereby, males controlling such sites accrue greater reproductive success (Emlen and Oring 1977; Andersson 1994; Brown et al. 1997; Shuster and Wade 2003) (see Fig. 1 Scenario 1a-c). This hypothesis has historically been investigated using three separate but non-mutually exclusive relationships (RHP vs. RV, RV vs. RS and RHP vs. RS). My meta-analysis supports the aforementioned hypothesis on four grounds. First, the global mean effect size for each relationship at the specieslevel (observational and experimental studies combined) were of similar magnitude $(r=0.37,0.45$ and 0.37$)$ and all significantly greater than zero. Second, these global effect sizes were not spurious as experimental studies showed a significant positive effect of male RHP and RV on male reproductive success. However, in only one case (RHP vs. RS) did the mean effect size based on experiments significantly outweigh the mean effect based on observations. Third, partial correlations showed that males with greater RHP had higher reproductive success while statistically controlling for resource-value and males controlling better resources had greater reproductive success while statistically controlling for male RHP. Finally, an analysis of a subset of 22 species for which all relationships have been quantified showed that all three effect sizes were of similar magnitude and, on average, significantly positive.

The interaction plot suggests that the magnitude and sign of a particular relationship can differ widely among species (Fig. 3). For example, male sand tilefish, Malacanthus plumieri, with greater RHP do not hold better resources nor do they gain greater reproductive success; however, sites of greater resource-value host males with higher reproductive success (see Fig. 1 Scenarios 2a, d and e). This result suggests that either resource-value is more important to female sand tilefish than male phenotype or perhaps, more importantly, researchers have incorrectly identified the traits determining RHP (see below). In contrast, male yellowshouldered widowbirds, Euplectes macrourus, with greater 
Table 2 Summary statistics for the relationship between resource-value (RV) and reproductive success (RS) at the species level of analysis

\begin{tabular}{|c|c|c|c|c|c|c|c|c|}
\hline & \multicolumn{3}{|c|}{ Effect size } & \multicolumn{3}{|c|}{ Effect size heterogeneity ${ }^{a}$} & \multirow[b]{2}{*}{ Fail safe no. } & \multirow[b]{2}{*}{$r$-bias } \\
\hline & $n_{\mathrm{e}}$ & $r$ & $95 \% \mathrm{CI}$ & $Q_{\mathrm{w}}$ & $d f$ & $P$ & & \\
\hline All species & 40 & 0.45 & $0.34-0.55$ & $79.6^{\mathrm{b}}$ & 39 & $<0.001$ & $1104^{\mathrm{c}}$ & -0.27 \\
\hline Quality & 29 & 0.42 & $0.30-0.55$ & 75.1 & 28 & $<0.001$ & $712^{\mathrm{c}}$ & -0.36 \\
\hline Size & 19 & 0.39 & $0.17-0.58$ & 15.1 & 18 & 0.66 & 49 & -0.08 \\
\hline Ownership & 2 & 0.31 & $0.25-0.35$ & - & - & - & - & - \\
\hline Insect & 14 & 0.50 & $0.36-0.69$ & 51.6 & 13 & $<0.001^{\mathrm{d}}$ & $287^{\mathrm{c}}$ & -0.39 \\
\hline Bird & 10 & 0.44 & $0.20-0.68$ & 84.8 & 9 & $<0.001^{\mathrm{e}}$ & $234^{\mathrm{c}}$ & -0.15 \\
\hline Fish & 7 & 0.41 & $0.19-0.60$ & 12.8 & 6 & $0.03^{\mathrm{f}}$ & 42 & -0.14 \\
\hline Mammal & 4 & 0.38 & $0.20-0.57$ & - & - & - & - & - \\
\hline Crustacean & 2 & 0.006 & $-0.15-0.25$ & - & - & - & - & - \\
\hline Amphibian & 2 & 0.58 & $0.51-0.64$ & - & - & - & - & - \\
\hline Reptile & 1 & 0.68 & - & - & - & - & - & - \\
\hline
\end{tabular}

See Table 1 for description of column headings

${ }^{a}$ Does not include taxa with $n_{\mathrm{e}}<5$

${ }^{\mathrm{b}} Q_{\mathrm{T}}$ because no data structure

${ }^{\mathrm{c}}$ Rosenthal's fail-safe number greater than $5 n_{\mathrm{e}}+10$

${ }^{\mathrm{d}}$ Removal of outlier $(r=0.99$, Rhagoletis boycei $): Q_{\mathrm{w}}=14.4, \mathrm{~d} f=12, P=0.28$

${ }^{\mathrm{e}}$ Removal of outlier $\left(r=-0.05\right.$, Euplectes macrourus): $Q_{\mathrm{w}}=6.1, d f=8, P=0.63$

${ }^{\mathrm{f}}$ Removal of outlier $(r=0.05$, Pomatoschistus minutus $): Q_{\mathrm{w}}=3.6, d f=4, P=0.46$

RHP have greater reproductive success. It appears though that higher-RHP males do not necessarily hold better territories nor do more-valuable territories increase male mating success (Savalli 1994a, b). Thus, female E. macrourus may choose male phenotype over resource characteristics. Alternatively, the resource characteristic sought by females in this species may have been inaccurately identified by the investigators (see below). Unfortu- nately, few of the effect sizes listed for the subset of 22 species were acquired experimentally (Table 4). By increasing our use of an experimental approach in investigations of resource-defence species we will not only more accurately identify what phenotypic traits and resource characteristics are important to male reproductive success but also better estimate the size of the effect these traits and characters have on male fitness (see also Candolin 2003).

Table 3 Summary statistics for the relationship between resource-holding potential (RHP) and reproductive success (RS) at the species level of analysis

\begin{tabular}{|c|c|c|c|c|c|c|c|c|}
\hline & \multicolumn{3}{|c|}{ Effect size } & \multicolumn{3}{|c|}{ Effect size heterogeneity ${ }^{a}$} & \multirow[b]{2}{*}{ Fail-safe no. } & \multirow[b]{2}{*}{$r$-bias } \\
\hline & $n_{\mathrm{e}}$ & $r$ & $95 \% \mathrm{CI}$ & $Q_{\mathrm{w}}$ & $d f$ & $P$ & & \\
\hline All species & 52 & 0.37 & $0.27-0.46$ & $60.2^{\mathrm{b}}$ & 51 & 0.18 & $951^{\mathrm{c}}$ & -0.26 \\
\hline Weapon & 5 & 0.32 & $0.28-0.35$ & 0.62 & 4 & 0.96 & $57^{\mathrm{c}}$ & -0.20 \\
\hline Signal & 21 & 0.43 & $0.28-0.58$ & 25.1 & 20 & 0.20 & $159^{\mathrm{c}}$ & -0.003 \\
\hline Age & 8 & 0.24 & $0.05-0.42$ & 4.7 & 7 & 0.69 & 3 & -0.18 \\
\hline Body size & 38 & 0.30 & $0.19-0.41$ & 35.9 & 37 & 0.52 & $296^{\mathrm{c}}$ & -0.28 \\
\hline Body condition & 4 & 0.49 & $0.14-0.79$ & - & - & - & - & - \\
\hline Other & 5 & 0.33 & $-0.08-0.59$ & 3.8 & 4 & 0.44 & 0 & 0.60 \\
\hline Insect & 25 & 0.39 & $0.25-0.54$ & 31.2 & 24 & 0.15 & $190^{\mathrm{c}}$ & $-0.48^{*}$ \\
\hline Bird & 12 & 0.27 & $0.10-0.42$ & 8.5 & 11 & 0.67 & 16 & 0.48 \\
\hline Fish & 7 & 0.42 & $0.14-0.65$ & 6.1 & 6 & 0.41 & 12 & -0.64 \\
\hline Mammal & 3 & 0.64 & $0.43-0.77$ & - & - & - & - & \\
\hline Crustacean & 2 & 0.10 & $0.06-0.16$ & - & - & - & - & \\
\hline Amphibian & 3 & 0.32 & $0.14-0.43$ & - & - & - & - & \\
\hline
\end{tabular}

See Table 1 for description of column headings

${ }^{a}$ Does not include taxa with $n_{\mathrm{e}}<5$

${ }^{\mathrm{b}} Q_{\mathrm{T}}$ because no data structure

${ }^{c}$ Rosenthal's fail-safe number greater than $5 n_{\mathrm{e}}+10$

${ }^{*} P<0.05$ 
Table 4 Effect sizes $(r)$ for each of three relationships for the subset of species in which all three relationships have been investigated

\begin{tabular}{|c|c|c|c|c|}
\hline Species & Taxon & RHP vs. RV & RHP vs. RS & RV vs. RS \\
\hline Acrocephalus arundinaceus & Bird & 0.374 & 0.302 & $0.340^{\mathrm{e}}$ \\
\hline Anthidium manicatum ${ }^{\mathrm{a}}$ & Insect & 0.350 & 0.314 & 0.290 \\
\hline Anthidium palliventre $\mathrm{a}^{\mathrm{a}}$ & Insect & 0.170 & 0.251 & 0.095 \\
\hline Anthidium porterae ${ }^{\mathrm{a}}$ & Insect & 0.483 & 0.486 & 0.002 \\
\hline Bothus poda ${ }^{\mathrm{a}}$ & Fish & 0.700 & 0.840 & 0.148 \\
\hline Euplectes macrourus ${ }^{\mathrm{a}}$ & Bird & $0.115^{\mathrm{e}}$ & $-0.044^{\mathrm{e}}$ & -0.054 \\
\hline Ficedula hypoleuca & Bird & $0.158^{\mathrm{e}}$ & $0.078^{\mathrm{e}}$ & 0.543 \\
\hline 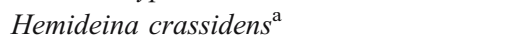 & Insect & $0.500^{\mathrm{e}}$ & $0.344^{\mathrm{e}}$ & $0.655^{\mathrm{e}}$ \\
\hline Kobus vardoni $i^{\mathrm{a}}$ & Mammal & 0.243 & 0.681 & 0.291 \\
\hline Malacanthus plumieri $^{\mathrm{a}}$ & Fish & -0.671 & -0.180 & 0.580 \\
\hline Megaloprepus coerulatus ${ }^{\mathrm{a}}$ & Insect & 0.528 & 0.173 & 0.384 \\
\hline Nannophya pygmaea & Insects & -0.262 & 0.517 & 0.589 \\
\hline Neacoryphus bicrucis & Insect & 0.116 & 0.382 & 0.814 \\
\hline Notobitus meleagris $^{\mathrm{a}}$ & Insect & 0.257 & 0.480 & 0.379 \\
\hline Ophioblennius atlanticus $^{\mathrm{a}}$ & Fish & 0.222 & 0.578 & 0.202 \\
\hline Phasianus colchicus ${ }^{\mathrm{a}}$ & Bird & $0.156^{\mathrm{e}}$ & 0.302 & 0.720 \\
\hline Pomatoschistus minutus & Fish & $0.506^{\mathrm{e}}$ & $0.485^{\mathrm{e}}$ & 0.053 \\
\hline Promerops cafer ${ }^{\mathrm{a}}$ & Bird & 0.160 & -0.254 & 0.617 \\
\hline Rana catesbeiana ${ }^{\mathrm{a}}$ & Amphibian & 0.509 & 0.400 & 0.514 \\
\hline Rana clamitans ${ }^{\mathrm{a}}$ & Amphibian & $0.625^{\mathrm{e}}$ & $0.430^{\mathrm{e}}$ & $0.638^{\mathrm{e}}$ \\
\hline Troglodytes troglodytes ${ }^{\mathrm{a}}$ & Bird & 0.330 & $0.497^{\mathrm{e}}$ & 0.540 \\
\hline Parablennius sanguinolentus parvicornis ${ }^{\mathrm{a}}$ & Fish & 0.437 & 0.678 & -0.35 \\
\hline
\end{tabular}

${ }^{a}$ All three relationships reported from single study (i.e. same date and location but not necessarily same publication)

${ }^{\mathrm{e}}$ Experimental effect size contributed to overall mean effect size

Trait identification and explained variation

The mean species-level effect sizes reported here were about twice as large as those typically reported for evolutionary ecological studies $(r=0.18-0.193$, Møller and Jennions 2002). Although the mean effect size for RHP vs. RV and RHP vs. RS were both $r=0.37$, male RHP traits only account for $14 \%$ of variation among males in the

Fig. 3 An interaction plot of effect size $(r)$ for the relationship between 1) male resource holding potential and resource value, 2) male resource holding potential and reproductive success and 3) resource value and reproductive success for each 22 species. See Table 4 for the taxa to which each species belongs

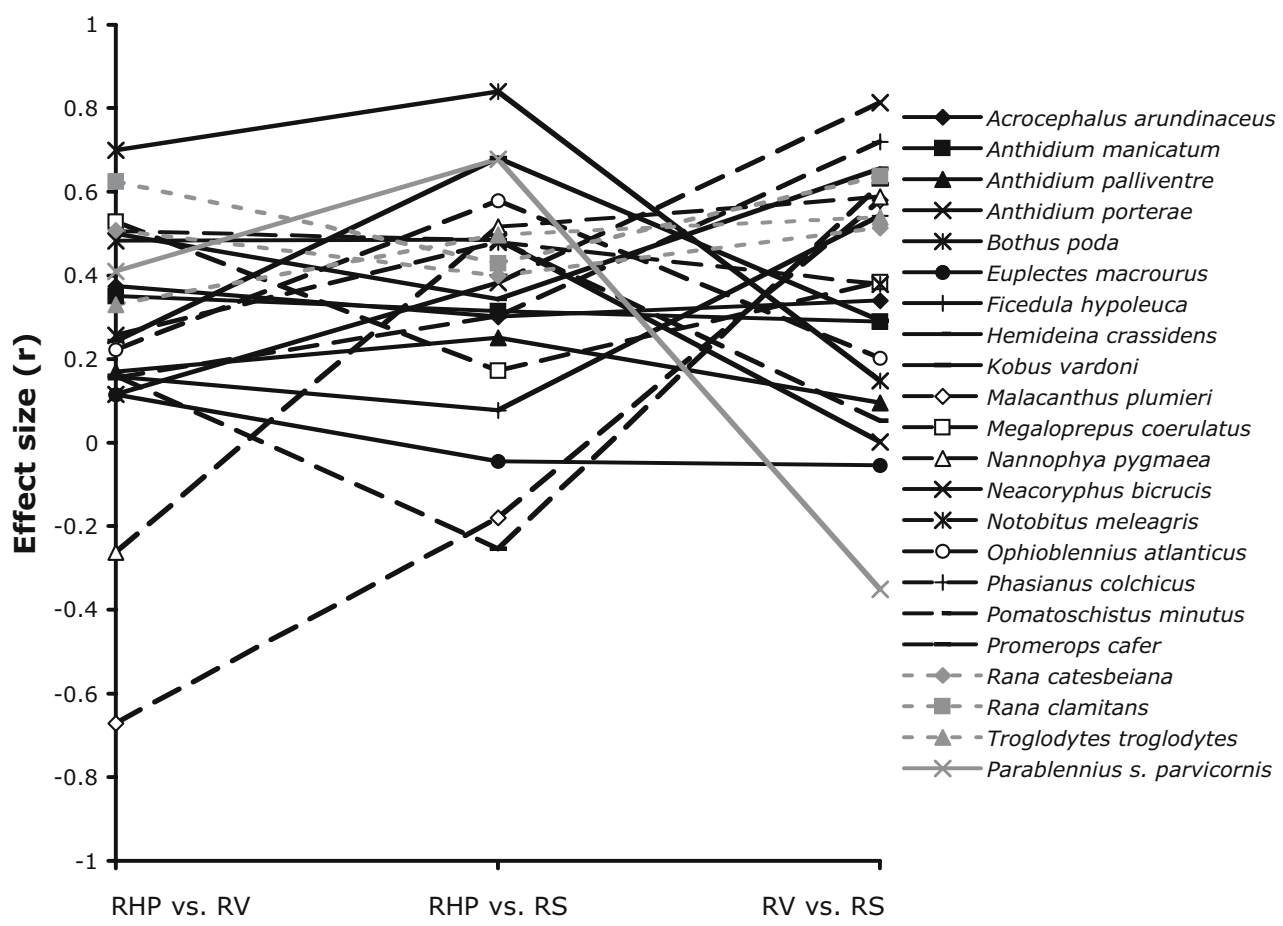

Relationship 
quality of the resource held and the reproductive success they acquired. The amount of explained variation was only marginally greater for RV vs. RS at $20 \%$. Thus, in order to detect a significant relationship in a single study between, for example male RHP and resource-value at the $0.05 \alpha$ level with $80 \%$ power, a minimum sample size of 52 is required. Such a sample size is larger than those typically used to investigate this relationship (Electronic Supplemental Material S2).

Contrary to prediction, only RHP vs. RS displayed a significantly larger average effect size for experimental studies compared with observational ones. This result is most likely due to our greater ability to identify and experimentally manipulate male traits that signal RHP compared with those representing resource quality; particularly, if resource quality is determined by something difficult to quantify, such as the greenness of the grass in a patch, for example. Alternatively, perhaps male RHP simply has a stronger effect on male reproductive success than resource quality. Perhaps our ability to identify, and then experimentally manipulate, resource quality will improve as our methods and techniques improve. For example, investigators are now able to, with relative ease, biochemically assay the nutritional quality of ingested materials (Heimpel et al. 2004), conduct remote video surveillance (Stewart et al. 1997) as well as better follow the movements of very small animals (e.g. crickets and dragonflies) with radiotelemetric devices (Lorch and Gwynne 2000). Consequently, our ability to unlock many of the secrets of an animal's life is continually improving and with that our ability to experimentally manipulate factors putatively important to male fitness.

Both the identity of the species used and the number of taxa upon which each effect size is based differed for each relationship. This could be a problem if, for example, insects tend to have a stronger relationship for RHP vs. RS and are over-represented in estimates of this particular relationship. Insects and birds dominated each of three relationships examined in this meta-analysis. For example, insects account for $47 \%, 48 \%$ and $37 \%$ of the species in the calculation of RHP vs. RV, RHP vs. RS and RV vs. RS, respectively. Fewer studies were available for mammals, fish, crustaceans, amphibians or reptiles.

That the mean effect sizes reported here were all relatively larger than those typically found in evolutionary ecological studies and significantly positive is partly due to researchers having selected a priori species that they believed to have a resource-defence based mating system. In other words, studies are typically conducted on species in which we know males defend resources etc. so a positive effect should come as no surprise. This is not always the case, however. For example, Christy and Schober (1994) did not support their hypothesis of resource-defence in a study on the fiddler crab Uca beebei. The paucity of published negative results at the sample- and study-level further supports the notion that investigators are not blindly testing whether an animal is territorial.

Four studies in my meta-analysis reported $r \sim 1.0$ (Hughes and Hughes 1985; Papaj 1994; Pryke and Andersson 2002; Pryke et al. 2002). Effect sizes of this magnitude are not the norm, particularly in field studies. Instead effect sizes, as evidenced in this meta-analysis, are often significantly greater than zero but far less than one because accurately identifying traits representing RHP or resource-value is difficult, measurement error is high and biological noise reduces the strength of the observed signal. I will address each factor below.

Investigators rarely know with high certainty which male trait(s) determine RHP or which characteristic defines the value of a territory for a given species, particularly when beginning research on a novel species. Instead, researchers typically correlate many traits putatively important to RHP with several different measures of territory quality or male reproductive success. Not surprisingly then, many traits turn out to be unimportant and consequently have a weak association with the type of resource held or with reproductive success. Because meta-analysis requires the inclusion of all relevant effect size estimates from each study, regardless of statistical significance, mean effect sizes tend to be underestimates. For example, although Pryke et al. (2002) reported a strong effect of collar colour (the determinant of male RHP) on territory size $(r \sim 1.0$, my calculation) in the red-collared widowbird, Euplectes ardens, the mean effect size for RHP vs. RV in this species was nearly halved at $r=0.52$ because of the inclusion in their analysis of some unimportant traits such as tail asymmetry and culmen length (see Andersson et al. 2002). This begs the interesting question as to whether the traits identified a posteriori as being important would be so in a replicate study (see Kelly 2006a), or was it simply by chance that this particular trait came out strongly in a large correlation matrix?

The significant heterogeneity among effect sizes observed for RV vs. RS is also likely to reflect our inability to target the resource characteristic(s) important in determining its value to females. Our ability to identify important traits does not appear to have improved with time, as there was no relationship between publication date and effect size (as observed in other biological relationships). I note that an improvement over time in how accurately we identify important traits does not necessarily have to be confined to one's own study species - investigators can heed the lessons learnt by those investigating organisms with similar morphology and/or behaviour. For example, in the megachilid bee Anthidium manicatum, Severinghaus et al. (1981) tested and supported the hypothesis that male mating 
success is dependent upon the number of flowers in a territory. This hypothesis was raised in an earlier study by Alcock et al. (1977) on the congeneric A. maculosum. Similarly effect size could increase with date of publication if investigators improve their knowledge of which resource/ territory characteristics are important to females as well as increase their accuracy in measuring mating success (e.g. through video surveillance of resource sites).

One way to get around the problem of underestimating the effect of single traits is to adopt a multivariate approach (e.g. principal components analysis, PCA) thereby permitting the reduction of several important and related traits to a single variable. Such an approach would be particularly beneficial if several different trait types (e.g. behavioural and structural) worked in conjunction to establish RHP. No study reported in this meta-analysis used PCA to reduce different types of traits into one RHP variable. More common, but still found in only four studies (Lebas 2001; Andersson et al. 2002; Forstmeier 2002; Pryke and Andersson 2003a, b), was the use of PCA to distil several measures of one trait-type (e.g. structural) to a single variable representing, for example, body size (e.g. tarsus, culmen and wing length in the red-shouldered widowbird Euplectes axillaris, Pryke and Andersson 2003a, b).

Reducing several traits to a principal component would also be beneficial in situations where male-male competition and female mate choice operate differently upon a trait (s). For example, Moore (1990) showed that in Libellula luctuosa male-male competition selects directionally for larger body size while there is stabilizing intersexual selection for males of intermediate body size but with increased wing pigmentation. Therefore, in species where this type of situation seems likely to arise it would be prudent to measure several traits representing body size (e.g. thorax width, wing length) and traits known to influence female mate choice (e.g. area of wing pigmentation, colour intensity), and then reduce these to two components representing traits important in intra- and inter-sexual selection, respectively.

Effect sizes larger than $r=0.30$ are rare in behavioural ecology, even for well-established relationships like those between sexually selected traits and reproductive success (Jennions et al. 2001; Møller and Jennions 2002). Several authors (e.g. Gontard-Danek and Møller 1999; Jennions et al. 2001) argue that low observed values are due to a high degree of noise and stochastic variation affecting biological relationships. For example, females may have strong mate preferences that might not be realized because preferred males are unavailable in a particular site or year, or because other females have already attached themselves to these males (Jennions et al. 2001). The extent to which noise contributes to diminishing an effect size estimate can be quantified experimentally (Gontard-Danek and Møller
1999), in the laboratory if possible, by exactly replicating the experiment with a different group of animals each time (see Kelly 2006a). If effect sizes of $r=0.37-0.45$ are the best we can achieve for well-established relationships in intensely-studied organisms, like those measured here, it is not surprising we typically find small effect sizes in evolutionary ecology studies (Møller and Jennions 2002).

I conclude by suggesting that an examination of the effect sizes generated in this meta-analysis can provide an index that allows us to explore how well we know our study species, within the constraints imposed by unaccountable sources of variation.

\section{Effect size by taxon}

My results show that, in general, males with greater RHP own better territories. This effect was strongest (and significant) for insects, birds and amphibians but not so for fishes. The lack of a strong effect in fishes may stem from the fact that contests for territories are often settled based on residency. For example, Jones (1981) showed that male-male fights in Pseudolabrus celidotus wrasses are won by the resident male. Therefore, although female choice is based on territory quality, stochastic processes random settlement - ultimately determine male reproductive success. Perhaps this is a general phenomenon among fishes, or at least among marine teleosts living on coral reefs (Nijman and Heuts 2000). Similarly, males with larger RHP accrued greater reproductive success overall but this effect was strongest (and significant) for insects, birds and amphibians.

Traits representing male dominance and resource quality

Among the studies I examined, body size was the most common trait studied by investigators as a predictor of male RHP, followed by signals (e.g. song repertoire size, tail length), weaponry, male age, body condition and 'other' (e.g. arrival date). That traits representing male RHP accounted for only $14 \%$ of the variation in resource-value and reproductive success, respectively, suggests that investigators may be misidentifying the relevant traits, or that factors other than phenotype, are important for controlling resources and accruing reproductive success. For example, arrival date may dictate male reproductive success. In birds, earlier-arriving individuals often acquire better territories and phenotypic traits, such as body size, need not be correlated with time of arrival (e.g. Hasselquist 1998).

All six types of RHP-traits showed a strong effect on a male's ability to hold high-value resources with both older and better-conditioned males holding better resources. That males in better condition are able to hold a better resource is understandable given competition for territories is often 
energetically demanding. The apparent success of older males is more difficult to explain; perhaps correlates of age, such as body size, are the actual causal factors responsible for the observed relationships (Brooks and Kemp 2001).

Males that accrue greater reproductive success tend to be in better condition or have greater signal value. Conversely, male age exhibited the weakest effect on reproductive success. This result was unexpected given that older animals in some taxa (e.g. mammals) tend to be larger and larger animals, which have greater RHP, are often found to have greater reproductive success (Andersson 1994). Contrary to this notion, however, is a growing body of empirical evidence showing that older animals may be less preferred by females (e.g. Hunt et al. 2004) and/ or suffer in male-male competition (e.g. Forsyth and Montgomerie 1987), possibly due to reduced energy stores (e.g. Marden and Waage 1990).

For the subset of species discussed above, the observed intraspecific differences in effect size and sign among the three relationships could be real or they could reflect inaccurate identification of the relevant trait(s). Moreover, because many of the studies used in this meta-analysis relied on natural phenotypic variation and were correlative, several confounding factors were not controlled. For example, population demography (e.g. male density, Borgia 1980; McLain 1992; operational sex ratio, Blanckenhorn et al. 2003), individual state (e.g. energy levels, Marden and Waage 1990; Plaistow and Siva-Jothy 1996), local environmental conditions (e.g. temperature, Switzer 2002) and ecological factors (e.g. level of predation risk, Gwynne and O'Neill 1980) are all known to influence a male's tenure on a territory. The best way to combat problems associated with confounding factors and misidentification of important traits is to systematically manipulate different male traits and resource characters and then test which has the greatest effect on male reproductive success. Implementing this approach, however, is not always possible if working on a large animal or one that requires large territories. Perhaps, the best we can do is to quantify the relationship of interest in several populations throughout the breeding season to assess the generality of the relationship (Kelly 2006a).

Ultimately, investigators need to test all three relationships within the same species in order to appropriately determine the underlying mechanism responsible for a male's reproductive success. For example, that a male with apparently large RHP has high mating success does not necessarily mean that he controls more-valuable resources females may prefer males with larger trait values independent of resource characteristics - nor does it mean that he will have greater reproductive success if females use the sperm of other males (Fig. 1) (Candolin 2003). Testing the strength of all three relationships, however, will compound the problems associated with testing a single relationship, particularly because factors affecting male tenure vary spatiotemporally. To reduce error associated with differences in location and time of year, researchers should test the three relationships concurrently at the same site. In the seed bug Neacoryphus bicrucis, for example, the advantage of male body size in defending territories and acquiring mates decreases as population density increases from early(mid-April) to mid-season (early May) (McLain 1992). At higher densities, (i.e. early May) the otherwise positive correlation between resource value and male body size (RHP) breaks down with males eventually abandoning resource-defence and entering into scramble competition. Therefore, if the three main relationships examined in the present meta-analysis were studied at different times of the year in $N$. bicrucis an inaccurate picture could emerge regarding the importance of male body size and resource value on male mating success. In the rare case that an investigator has tested all three relationships within a species, they have apparently recognized the potential confounds and examined all relationships concurrently at the same location (18/22 species, Table 4). Very few studies have experimentally tested the interrelationships of male RHP, resource-value and male mating or reproductive success in the laboratory or used partial correlations to statistically account for potentially confounding factors (Lindström 1992; Kelly 2006b).

In conclusion, (i) investigators must quantify within a species each of the three relationships addressed in this meta-analysis and test the alternative hypotheses outlined in Fig. 1 Scenario 1-3; (ii) studies require larger sample sizes $(N>52)$ to detect statistically significant relationships; (iii) once the putatively important trait(s) has been identified (by using a correlative approach and relying upon natural phenotypic variation), manipulative experiments with proper controls and reciprocal treatments (i.e. good male on poor resource and vice versa) should be employed, preferably in the laboratory in order to illuminate the independent effects of male phenotypic traits and resource characteristics on male reproductive success (at the very least we should statistically control for confounding variables (i.e. resource characteristics and male traits) by using analysis of covariance or partial correlations); (iv) investigators must control for spatiotemporal factors in field studies by testing each relationship at the same time and place; (v) investigators should quantify the degree to which biological noise contributes to relationships by conducting experiments (sensu Gontard-Danek and Møller 1999); (vi) we need to expand the list of taxa used to address the above hypotheses, in particular, we need more studies on fishes, reptiles, amphibians, crustaceans and mammals; and finally (vii) because we are ultimately interested in the benefits to male fitness of holding a particular resource or possessing particular traits, we need accurate measures of mating success. 
Acknowledgements I thank Darryl Gwynne and Michael Jennions for advice and comments on the manuscript. This study was supported by an operating grant from National Science and Research Engineering Council (NSERC) of Canada to Darryl Gwynne and by an NSERC Postdoctoral Fellowship and an Australian National University Faculty of Science support grant to the author.

\section{References}

Alatalo RV, Lundberg A, Glynn C (1986) Female pied flycatchers choose territory quality and not male characteristics. Nature 323:152-153

Alcock J (1987) The effects of experimental manipulation of resources on the behavior of two calopterygid damselflies that exhibit resource-defense polygyny. Can J Zool 65:2475-2482

Alcock J (1995) Body size and its effect on male-male competition in Hylaeus alcyoneus (Hymenoptera, Colletidae). J Insect Behav 8:149-159

Alcock J, Eickwort GC, Eickwort KR (1977) The reproductive behaviour of Anthidium maculosum (Hymenoptera: Megachilidae) and the evolutionary significance of multiple copulations by females. Behav Ecol Sociobiol 2:385-396

Alcock JA, Houston TF (1987) Resource defense and alternative mating tactics in the Banksia bee, Hylaeus alcyoneus (Erichson). Ethology 76:177-188

Andersson M (1994) Sexual Selection. Princeton University Press, Princeton, $\mathrm{NJ}$

Andersson S, Pryke SR, Ornborg J, Lawes MJ, Andersson M (2002) Multiple receivers, multiple ornaments, and a trade-off between agonistic and epigamic signaling in a widowbird. Am Nat 160:683-691

Arnqvist G, Rowe L (2005) Sexual Conflict. Princeton University Press, Princeton

Arnqvist G, Wooster D (1995) Meta-analysis: synthesizing research findings in ecology and evolution. Trends Ecol Evol 10:236-240

Backwell PRY, Passmore NI (1996) Time constraints and multiple choice criteria in the sampling behaviour and mate choice of the fiddler crab, Uca annulipes. Behav Ecol Sociobiol 38:407-416

Baird TA (1988) Female and male territoriality and mating system of the sand tilefish, Malacanthus plumieri. Environ Biol Fishes 22:101-116

Baird TA, Liley NR (1989) The evolutionary significance of harem polygyny in the sand tilefish, Malacanthus plumieri: Resource or female defence? Anim Behav 38:817-829

Baker RR (1983) Insect territoriality. Annu Rev Entomol 28:65-89

Ballentine B, Hill GE (2003) Female mate choice in relation to structural plumage coloration in Blue Grosbeaks. Condor 105:593-598

Balmford A, Rosser AM, Albon SD (1992) Correlates of female choice in resource-defending antelope. Behav Ecol Sociobiol 31:107-114

Begg C (1994) Publication bias. In: Cooper H, Hedges LV (eds) The Handbook of Research Synthesis. Russell Sage Foundation, New York, NY, pp 399-409

Blanckenhorn WU, Frei J, Birrer M (2003) The effect of female arrivals on mate monopolization in the yellow dung fly. Behav Ecol Sociobiol 54:65-70

Borgia G (1980) Sexual competition in Scatophaga stercoraria: sizeand density-related changes in male ability to capture females. Behaviour 75:185-206

Brooks R, Kemp DJ (2001) Can older males deliver the good genes? Trends Ecol Evol 16:308-313
Brown WD, Crespi BJ, Choe JC (1997) Sexual conflict and the evolution of mating systems. In: Choe JC, Crespi BJ (eds) The Evolution of Mating Systems in Insects and Arachnids. Cambridge University Press, Cambridge, pp 130-145

Calf KM, Downs CT, Cherry MI (2003) Territoriality and breeding success in the Cape Sugarbird (Promerops cafer). Emu 103:2935

Candolin U (2003) The use of multiple cues in mate choice. Biol Rev 78:575-595

Carey PW (1991) Resource-defense polygyny and male territory quality in the New Zealand fur seal. Ethology 88:63-79

Carranza J (1995) Female attraction by males versus sites in territorial rutting red deer. Anim Behav 50:445-453

Carranza J, Fernez-Llario P, Gomendio M (1996) Correlates of territoriality in rutting red deer. Ethology 102:793-805

Carvalho N, Afonso P, Santos RSA (2003) The haremic mating system and mate choice in the wide-eyed flounder, Bothus podas. Environ Biol Fishes 66:249-258

Catchpole CK (1986) Song repertoires and reproductive success in the great reed warbler Acrocephalus arundinaceus. Behav Ecol Sociobiol 19:439-445

Christy JH, Schober UM (1994) A test for resource-defense mating in the fiddler crab Uca beebei. Anim Behav 48:795-802

Conrad KF, Pritchard G (1992) An ecological classification of odonate mating systems - the relative influence of natural, intersexual and intrasexual selection on males. Biol J Linean Soc 45:255-269

Convey P (1989) Influences on the choice between territorial and satellite behaviour in male Libellula quadrimaculata Linn. (Odonata: Libellulidae). Behaviour 109:125-141

Cooper H, Hedges LV (1994) The Handbook of Research Synthesis. Russel Sage Foundation, New York, NY

Cordoba-Aguilar A (2002) Wing pigmentation in territorial male damselflies, Calopteryx haemorrhoidalis: a possible relation to sexual selection. Anim Behav 63:759-766

Côte IM, Hunte W (1989) Male and female choice in the redlip blenny: why bigger is better. Anim Behav 38:78-88

Dale S, Rinden H, Slagsvold T (1992) Competition for a mate restricts mate search of female pied flycatchers. Behav Ecol Sociobiol 30:165-176

Dale S, Slagsvold T (1990) Random settlement of female pied flycatchers, Ficedula hypoleuca: Significance of male territory size. Anim Behav 39:231-243

Debuse VJ, Addison JT, Reynolds JD (2003) Effects of breeding site density on competition and sexual selection in the European lobster. Behav Ecology 14:396-402

Downhower JF, Brown L (1980) Mate preferences of female mottled sculpins, Cottus bairdi. Anim Behav 28:728-734

Duval S, Tweedie R (2000a) A nonparametric "trim and fill" method of accounting for publication bias in meta-analysis. J Amer Stat Assoc 95:89-98

Duval S, Tweedie R (2000b) Trim and fill: A simple funnel-plot-based method of testing and adjusting for publication bias in metaanalysis. Biometrics 56:455-463

Emlen ST, Oring LW (1977) Ecology, sexual selection, and the evolution of mating systems. Science 197:215-223

Evans MR, Burn JL (1996) An experimental analysis of mate choice in the wren: A monomorphic, polygynous passerine. Behavl Ecol 7:101-108

Fincke OM (1992) Consequences of larval ecology for territoriality and reproductive success of a neotropical damselfly. Ecology 73:449-462

Fiske P, Rintamäki PT, Karvonen E (1998) Mating success in lekking males: a meta-analysis. Behav Ecol 9:328-338

Fitzpatrick SM, Wellington WG (1983) Insect territoriality. Canad J Zool 61:471-486 
Forstmeier W (2002) Factors contributing to male mating success in the polygynous dusky warbler (Phylloscopus fuscatus). Behaviour 139:1361-1381

Forstmeier W, Leisler B (2004) Repertoire size, sexual selection, and offspring viability in the great reed warbler: changing patterns in space and time. Behav Ecol 15:555-563

Forsyth A, Alcock J (1990) Female mimicry and resource defense polygyny by males of a tropical rove beetle, Leistotrophus versicolor (Coleoptera: Staphylinidae). Behav Ecol Sociobiol 26:325-330

Forsyth A, Montgomerie RD (1987) Alternative reproductive tactics in the territorial damslefly Calopteryx maculata: sneaking by older males. Behav Ecol Sociobiol 21:73-81

Friedl TWP, Klump GM (1999) Determinants of male mating success in the red bishop (Euplectes orix). Behav Ecol Sociobiol 46:387399

Giacomello E, Rasotto MB (2005) Sexual dimorphism and male mating success in the tentacled blenny, Parablennius tentacularis (Teleostei: Blenniidae). Mar Biol 147:1221-1228

Goldsmith SK (1987) The mating system and alternative reproductive behaviors of Dendrobias mandibularis (Coleoptera: Cerambycidae). Behav Ecol Sociobiol 20:111-115

Goldsmith SK, Alcock J (1993) The mating chances of small males of the cerambycid beetle Trachyderes mandibularis differ in different environments (Coleoptera, Cerambycidae). J Insect Behav 6:351-360

Gontard-Danek MC, Møller AP (1999) The strength of sexual selection: a meta-analysis of bird studies. Behav Ecol 10:476486

Göransson G, von Schantz T, Fröberg I, Helgée A, Wittzell H (1990) Male characteristics, viability and harem size in the pheasant, Phasianus colchicus. Anim Behav 40:89-104

Gottlander K (1987) Variation in the song rate of the male pied flycatcher Ficedula hypoleuca: causes and consequences. Anim Behav 35:1037-1043

Grahn M, Goransson G, Vonschantz T (1993) Territory acquisition and mating success in pheasants, Phasianus colchicus: an experiment. Anim Behav 46:721-730

Greenfield MD, Minckley RL (1993) Acoustic duelling in tarbush grasshoppers: settlement of territorial contests via alternation of reliable signals. Ethology 95:309-326

Gwynne DT, Jamieson I (1998) Sexual selection and sexual dimorphism in a harem-polygynous insect, the alpine weta (Hemideina maori, Orthoptera Stenopelmatidae). Ethol Ecol Evol 10:393-402

Gwynne DT, O'Neill KM (1980) Territoriality in digger wasps results in sex biased predation on males (Hymenoptera: Sphecidae, Philanthus). J Kans Entomol Soc 53:220-224

Hansson B, Bensch S, Hasselquist D (2000) Patterns of nest predation contribute to polygyny in the great reed warbler. Ecology $81: 319-328$

Hasselquist D (1998) Polygyny in great reed warblers: A long-term study of factors contributing to male fitness. Ecology 79:23762390

Heckel G, von Helversen O (2002) Male tactics and reproductive success in the harem polygynous bat Saccopteryx bilineata. Behav Ecol 13:750-756

Hedges LV, Olkin I (1985) Statistical Methods for Meta-analysis. Academic Press, Orlando, FL

Heimpel GE, Lee JC, Wu ZS, Weiser L, Wackers F, Jervis MA (2004) Gut sugar analysis in field-caught parasitoids: adapting methods originally developed for biting flies. Int J Pest Manag 50:193198

Hernandez MIM, Benson WW (1998) Small-male advantage in the territorial tropical butterfly Heliconius sara (Nymphalidae): a paradoxical strategy? Anim Behav 56:533-540
Hoffmann AA (1987) A laboratory study of male territoriality in the sibling species Drosophila melanogaster and D. simulans. Anim Behav 35:807-818

Hoffmann AA (1990) The influence of age and experience with conspecifics on territorial behavior in Drosophila melanogaster. J Insect Behav 3:1-12

Hoi-Leitner M, Nechtelberger H, Hoi H (1995) Song rate as a signal for nest-site quality in blackcaps (Sylvia atricapilla). Behav Ecol Sociobiol 37:399-405

Howard RD (1978a) The evolution of mating strategies in bullfrogs, Rana catesbeiana. Evolution 32:850-871

Howard RD (1978b) The influence of male-defended oviposition sites on early embryo mortality in bullfrogs. Ecology 59:789-798

Hughes AL, Hughes MK (1985) Female choice of mates in a polygynous insect, the whitespotted sawyer Monochamus scutellatus. Behav Ecol Sociobiol 17:385-387

Hunt J, Brooks R, Jennions MD, Smith MJ, Bentsen CL, Bussiere LF (2004) High-quality male field crickets invest heavily in sexual display but die young. Nature 432:1024-1027

Jennions MD (1998) Tibial coloration, fluctuating asymmetry and female choice behaviour in the damselfly Platycypha caligata. Anim Behav 55:1517-1528

Jennions MD, Moller AP, Hunt J (2004) Meta-analysis can "fail": reply to Kotiaho and Tomkins. Oikos 104:191-193

Jennions MD, Møller AP (2002) Publication bias in ecology and evolution: an empirical assessment using the 'trim and fill' method. Biol Rev 77:211-222

Jennions MD, Møller AP, Petrie M (2001) Sexually selected traits and adult survival: A meta-analysis. Q Rev Biol 76:3-36

Jones GP (1981) Spawning-site choice by female Pseudolabrus celidotus (Pisces: Labridae) and its influence on the mating system. Behav Ecol Sociobiol 8:129-142

Kelly CD (2005) Allometry and sexual selection of male weaponry in Wellington tree weta, Hemideina crassidens. Behav Ecol $16: 145-152$

Kelly CD (2006a) Replicating empirical research in behavioral ecology: How and Why it should be done but rarely ever is. Q Rev Biol 81:221-236

Kelly CD (2006b) The relationship between resource control, association with females and male weapon size in a maledominance insect. Ethology 112:362-369

Kelly CD (2006c) Resource quality or harem size: What influences male tenure at refuge sites in tree weta (Orthoptera: Anostostomatidae)? Behav Ecol Sociobiol 60:175-183

Keyser AJ, Hill GE (2000) Structurally based plumage coloration is an honest signal of quality in male blue grosbeaks. Behav Ecol 11:202-209

Kirkpatrick M, Ryan MJ (1991) The evolution of mating preferences and the paradox of the lek. Nature 350:33-38

Koenig WD, Albano SS (1985) Patterns of territoriality and mating success in the white-tailed skimmer Plathemis lydia (Odonata: Anisoptera). Am Midl Nat 114:1-12

Koricheva J (2003) Non-significant results in ecology: a burden or a blessing in disguise? Oikos 102:397-401

Kotiaho JS, Tomkins JL (2002) Meta-analysis, can it ever fail? Oikos 96:551-553

Kroon FJ, de Graaf M, Liley NR (2000) Social organisation and competition for refuges and nest sites in Coryphopterus nicholsii (Gobiidae), a temperate protogynous reef fish. Environ Biol Fishes 57:401-411

Kwiatkowski MA, Sullivan BK (2002) Mating system structure and population density in a polygynous lizard, Sauromalus obesus (= ater). Behav Ecology 13:201-208

Lampe HM, Espmark YO (2003) Mate choice in pied flycatchers Ficedula hypoleuca: can females use song to find high-quality males and territories? Ibis 145:E24-E33 
Lebas NR (2001) Microsatellite determination of male reproductive success in a natural population of the territorial ornate dragon lizard, Ctenophorus ornatus. Mol Ecol 10:193-203

Lightbody JP, Weatherhead PJ (1987) Polygyny in the yellow-headed blackbird: female choice versus male competition. Anim Behav 35:1670-1684

Lightbody JP, Weatherhead PJ (1988) Female settling patterns and polygyny: tests of a neutral-mate-choice hypothesis. Am Nat 132:20-33

Lindström K (1988) Male-male competition for nest sites in the sand goby, Pomatoschistus minutus. Oikos 53:67-73

Lindström K (1992) The effect of resource holding potential, nest size and information about resource quality on the outcome of intruder-owner conflicts in the sand goby. Behav Ecol Sociobiol 30:53-58

Lindström K, Pampoulie C (2005) Effects of resource holding potential and resource value on tenure at nest sites in sand gobies. Behav Ecol 16:70-74

Lindström K, Seppä T (1996) The environmental potential for polygyny and sexual selection in the sand goby, Pomatoschistus minutus. Proc R Soc Lond B 263:1319-1323

Lorch PD, Gwynne DT (2000) Radio-telemetric evidence of migration in the gregarious but not the solitary morph of the Mormon cricket (Anabrus simplex: Orthoptera: Tettigoniidae). Naturwissenschaften 87:370-372

Maher CR, Lott DF (2000) A review of ecological determinants of territoriality within vertebrate species. Am Midl Nat 143:1-29

Marden JH, Waage JK (1990) Escalated damselfly territorial contests are energetic wars of attrition. Anim Behav 39:954-959

McLain DK (1984) Host plant density and territorial behavior of the seed bug, Neacoryphus bicrucis (Hemiptera: Lygaeidae). Behav Ecol Sociobiol 14:181-187

McLain DK (1992) Population density and the intensity of sexual selection on body length in spatially or temporally restricted natural populations of a seed bug. Behav Ecol Sociobiol 30:347356

Miller GR, Watson A (1978) erritories and food plant of individual red grouse: I. Territory size, number of mates and brood size compared with abundance, production and diversity of heather. J Anim Ecol 47:293-305

Miyatake T (1993) Male-male aggressive behavior is changed by body-size difference in the leaf-footed plant bug, Leptoglossus australis, Fabricius (Heteroptera, Coreidae). J Ethol 11:63-65

Miyatake T (1995) Territorial mating aggregation in the bamboo bug, Notobitus meleagris, Fabricius (Heteroptera: Coreidae). J Ethol 13:185-189

Miyatake T (2002) Multi-male mating aggregation in Notobitus meleagris (Hemiptera: Coreidae). Ann Entomol Soc Am 95:340-344

Moore AJ (1990) The evolution of sexual dimorphsim by sexual selection: The separate effects of intrasexual and intersexual selection. Evolution 44:315-331

Møller AP, Jennions MD (2001a) How important are direct fitness benefits of sexual selection? Naturwissenschaften 88:401-415

Møller AP, Jennions MD (2001b) Testing and adjusting for publication bias. Trends Ecol Evol 16:580-586

Møller AP, Jennions MD (2002) How much variance can be explained by ecologists and evolutionary biologists? Oecologia 132:492-500

Møller AP, Thornhill R (1998) Bilateral symmetry and sexual selection: a meta-analysis. Am Nat 151:174-192

Møller AP, Thornhill R, Gangestad SW (2005) Direct and indirect tests for publication bias: asymmetry and sexual selection. Anim Behav 70:497-506

Nijman V, Heuts BA (2000) Effect of environmental enrichment upon resource holding power in fish in prior residence situations. Behav Processes 49:77-83
Oliveira RF, Carvalho N, Miranda J, Goncalves EJ, Grober M, Santos RS (2002) The relationship between the presence of satellite males and nest-holders' mating success in the Azorean rock-pool blenny Parablennius sanguinolentus parvicornis. Ethology 108:223-235

Oliveira RF, Miranda JA, Carvalho N, Goncalves EJ, Grober MS, Santos RS (2000) Male mating success in the Azorean rock-pool blenny: the effects of body size, male behaviour and nest characteristics. J Fish Biol 57:1416-1428

Otronen M (1984a) Male contests for territories and females in the fly Dryomyza anilis. Anim Behav 32:891-898

Otronen M (1984b) The effect of differences in body size on the male territorial system of the fly Dryomyza anilis. Anim Behav 32:882-890

Palmer AR (1999) Detecting publication bias in meta-analyses: A case study of fluctuating asymmetry and sexual selection. Am Nat 154:220-233

Papaj DR (1994) Oviposition site guarding by male walnut flies and its possible consequences for mating success. Behav Ecol Sociobiol 34:187-195

Papeschi A, Carroll JP, Dessi-Fulgheri F (2003) Wattle size is correlated with male territorial rank in juvenile ring-necked pheasants. Condor 105:362-366

Parish DMB, Coulson JC (1998) Parental investment, reproductive success and polygyny in the lapwing, Vanellus vanellus. Anim Behav 56:1161-1167

Parker GA (1974) Assessment strategy and evolution of fighting behavior. J Theor Biol 47:223-243

Plaistow S, Siva-Jothy MT (1996) Energetic constraints and male mate-securing tactics in the damselfly Calopteryx splendens xanthostoma (Charpentier). Proc R Soc Lond B 263:1233-1238

Pomiankowski AN (1988) The evolution of female mate preferences for male genetic quality. Oxf Surv Evol Biol 5:136-184

Powers DR (1987) Effects of variation in food quality on the breeding territoriality of the male Anna hummingbird. Condor 89:103-111

Pribil S, Searcy WA (2001) Experimental confirmation of the polygyny threshold model for red-winged blackbirds. Proc $\mathrm{R}$ Soc Lond B 268:1643-1646

Pryke SR, Andersson S (2002) A generalized female bias for long tails in a short-tailed widowbird. Proc R Soc Lond B 269:2141-2146

Pryke SR, Andersson S (2003a) Carotenoid-based epaulettes reveal male competitive ability: experiments with resident and floater red-shouldered widowbirds. Anim Behav 66:217-224

Pryke SR, Andersson S (2003b) Carotenoid-based status signalling in red-shouldered widowbirds (Euplectes axillaris): epaulet size and redness affect captive and territorial competition. Behav Ecol Sociobiol 53:393-401

Pryke SR, Andersson S, Lawes MJ (2001) Sexual selection of multiple handicaps in the red-collared widowbird: Female choice of tail length but not carotenoid display. Evolution 55:1452-1463

Pryke SR, Andersson S, Lawes MJ, Piper SE (2002) Carotenoid status signaling in captive and wild red-collared widowbirds: independent effects of badge size and color. Behav Ecol 13:622-631

Reaney LT, Backwell PRY (2007) Temporal constraints and female preference for burrow width in the fiddler crab, Uca mjoebergi. Behav Ecol Sociobiol 61:1515-1521

Reid ML, Stamps JA (1997) Female mate choice tactics in a resourcebased mating system: Field tests of alternative models. Am Nat 150:98-121

Reynolds JD, Gross MR (1990) Costs and benefits of female mate choice: is there a lek paradox? Am Nat 136:230-243

Robertson HM (1982) Mating behaviour and its relationship to territoriality in Platycypha caligata (Selys) (Odonata: Chlorocyphidae). Behaviour 79:11-27

Robertson JGM (1986) Male territoriality, fighting and assessment of fighting ability in the Australian frog Uperoleia rugosa. Anim Behav 34:763-772 
Roithmair ME (1992) Territoriality and male mating success in the dart-poison frog, Epipedobates femoralis (Dendrobatidae, Anura). Ethology 92:331-343

Rosenberg MS, Adams DC, Gurevitch J (2000) MetaWin: Statistical Software for Meta-Analysis. 2nd edn. Sinauer Associates Inc., Sunderland, MS

Rosenthal R (1991) Meta-analytic Procedures for Social Research, 2nd edn. Sage, London

Rosenthal R (1994) Parametric measures of effect size. In: Cooper H, Hedges LV (eds) The Handbook of Research Synthesis. Russell Sage Foundation, New York, NY, pp 231-244

Savalli UM (1994a) Mate choice in the yellow-shouldered widowbird: Correlates of male attractiveness. Behav Ecol Sociobiol 35:227234

Savalli UM (1994b) Tail length affects territory ownership in the yellow-shouldered widowbird. Anim Behav 48:105-111

Searcy WA (1979) Female choice of mates: a general model for birds and its application to red-winged blackbirds (Agelaius phoeniceus). Am Nat 114:77-100

Severinghaus LL, Kurtak BH, Eickwort GC (1981) The reproductive behavior of Anthidium manicatum (Hymenoptera: Megachilidae) and the significance of size for territorial males. Behav Ecol Sociobiol 9:51-58

Shuster SM (1987) Alternative reproductive behaviors: three discrete male morphs in Paracerceis sculpta, an intertidal isopod from the northern Gulf of California. J Crustac Biol 7:318-327

Shuster SM (1992) The Reproductive-Behavior of Alpha-Male, BetaMale, and Gamma-Male Morphs in Paracerceis-Sculpta, a Marine Isopod Crustacean. Behaviour 121:231-258

Shuster SM, Wade MJ (1991) Equal mating success among male reproductive strategies in a marine isopod. Nature 350:608-610

Shuster SM, Wade MJ (2003) Mating Systems and Strategies. Princeton University Press, Princeton, NJ

Siva-Jothy MT (1999) Male wing pigmentation may affect reproductive success via female choice in a calopterygid damselfly (Zygoptera). Behaviour 136:1365-1377

Stewart PD, Ellwood SA, Macdonald DW (1997) Remote videosurveillance of wildlife - an introduction from experience with the European badger Meles meles. Mamm Rev 27:185-204

Switzer PV (2002) Territory quality, habitat selection, and competition in the amberwing dragonfly, Perithemis tenera (Say) (Odonata:
Libellulidae): Population patterns as a consequence of individual behavior. J Kans Entomol Soc 75:145-157

Thompson S (1986) Male spawning success and female choice in the mottled triplefin, Forsterygion varium (Pisces: Tripterygiidae). Anim Behav 34:580-589

Thornhill R (1983) Cryptic female choice and its implications in the scorpionfly Harpobittacus nigriceps. Am Nat 122:765-788

Thornhill R, Alcock J (1983) The Evolution of Insect Mating Systems. Harvard University Press, Cambridge, MA

Thornhill R, Møller AP (1998) The relative importance of size and asymmetry in sexual selection. Behav Ecol 9:546-551

Tomkins JL, Kotiaho JS (2004) Publication bias in meta-analysis: seeing the wood for the trees. Oikos 104:194-196

Torres-Vila LM, Jennions MD (2005) Male mating history and female fecundity in the Lepidoptera: do male virgins make better partners? Behav Ecol Sociobiol 57:318-326

Tsubaki Y, Ono T (1986) Competition for territorial sites and alternative mating tactics in the dragonfly, Nannophya pygmaea Rambur (Odonata: Libellulidae). Behaviour 97:234-252

Tsubaki Y, Ono T (1987) Effects of age and body size on the male territorial system of the dragonfly, Nannophya pygmaea (Odonata: Libellulidae). Anim Behav 35:518-525

Villalobos EM, Shelly TE (1991) Correlates of male mating success in two species of Anthidium bees (Hymenoptera, Megachilidae). Behav Ecol Sociobiol 29:47-53

von Schantz T, Grahn M, Göransson G (1994) Intersexual selection and reproductive success in the pheasant Phasianus colchicus. Am Nat 144:510-527

Waage JK (1984) Female and male interactions during courtship in Calopteryx maculata and Calopteryx dimidiata (Odonata, Calopterygidae): Influence of oviposition behavior. Anim Behav $32: 400-404$

Wells KD (1977) Territoriality and male mating success in the green frog (Rana clamitans). Ecology 58:750-762

Wittenberger JF (1983) Tactics of mate choice. In: Bateson P (ed) Mate Choice. Cambridge University Press, Cambridge, pp 435-447

Wootton JT, Bollinger EK, Hibbard CJ (1986) Mating systems in homogeneous habitats: the effects of female uncertainty, knowledge costs, and random settlement. Am Nat 128:499-512

Yasukawa K (1981) Male quality and female choice of mate in the redwinged blackbird (Agelaius phoeniceus). Ecology 62:922-929 